\title{
THE DIAGNOSTIC VALUE OF PRE-HOSPITAI ARTERIAL BLOOD GAS
}

Bering, Caroline B. MD ${ }^{1}$, Zincuk, Yecatarina MD ${ }^{2}$, Zwisler, Stine T. MD PhD ${ }^{1,2}$, ZinCUK, AleKSANDER MD ${ }^{1,2}$ \& MiKKELSEN, SøREN MD PHD ${ }^{1,2,3}$

${ }^{1}$ Department of Anaesthesiology \& Intensive Care, Odense University Hospital, Denmark

The Mobile Emergency Care Unit, Department of Anaesthesiology \& Intensive Care, Odense University Hospital, Denma ${ }^{3}$ Department of Clinical Research, Odense University Hospital, Denmark

\section{INTRODUCTION}

Arterial blood gas analysis (ABG) is an important diagnostic tool in management of critically ill patients within the hospital. It is, however, unknown whether this diagnostic modality can contribute to a more exact diagnosis in a mixed population of critically ill patients prehospitally. The aim of this study was to establish the diagnostic value of pre-hospital ABG. We investigated whether more patients received specific diagnosis (according to the WHO ICD-10 classification) reducing the numbers of observational or symptomatic diagnosis (WHO ICD-10 classification chapters XVIII and XXI, respectively), when ABG was available pre-hospitally.

\section{METHOD}

This single-centre prospective randomised controlled trial was conducted at a pre-hospital service. We compared two groups of adults with acute critical illness and Glasgow Coma Score $(\mathrm{GCS})<13$ treated by a prehospital anaesthesiologist. All patients received standard care treatment. In the intervention group, an ABG was obtained and analysed at the emergency site. The primary outcome was the impact of $A B G$ on the pre-hospital tentative diagnosis. Furthermore, the Emergency Physician (EP) subjectively evaluated the usefulness of the $A B G$ in pre-hospital diagnostics immediately after the emergency run.

\section{RESULTS}

310 patients were randomized, 155 in each group. 53 patients were excluded in the ABG group and 35 patients in the non-ABG group. The main exclusion cause was failed post hoc consent from next-of-kin or family physician.

There were no differences in the percentage of patients given an observational or

symptomatic diagnosis pre-hospitally among the 2 groups. The EP reported that the ABG generally contributed positively to the treatment at the emergency site $(P<0,001)$ and furthermore contributed to a more precise diagnosis $(P=0,001)$

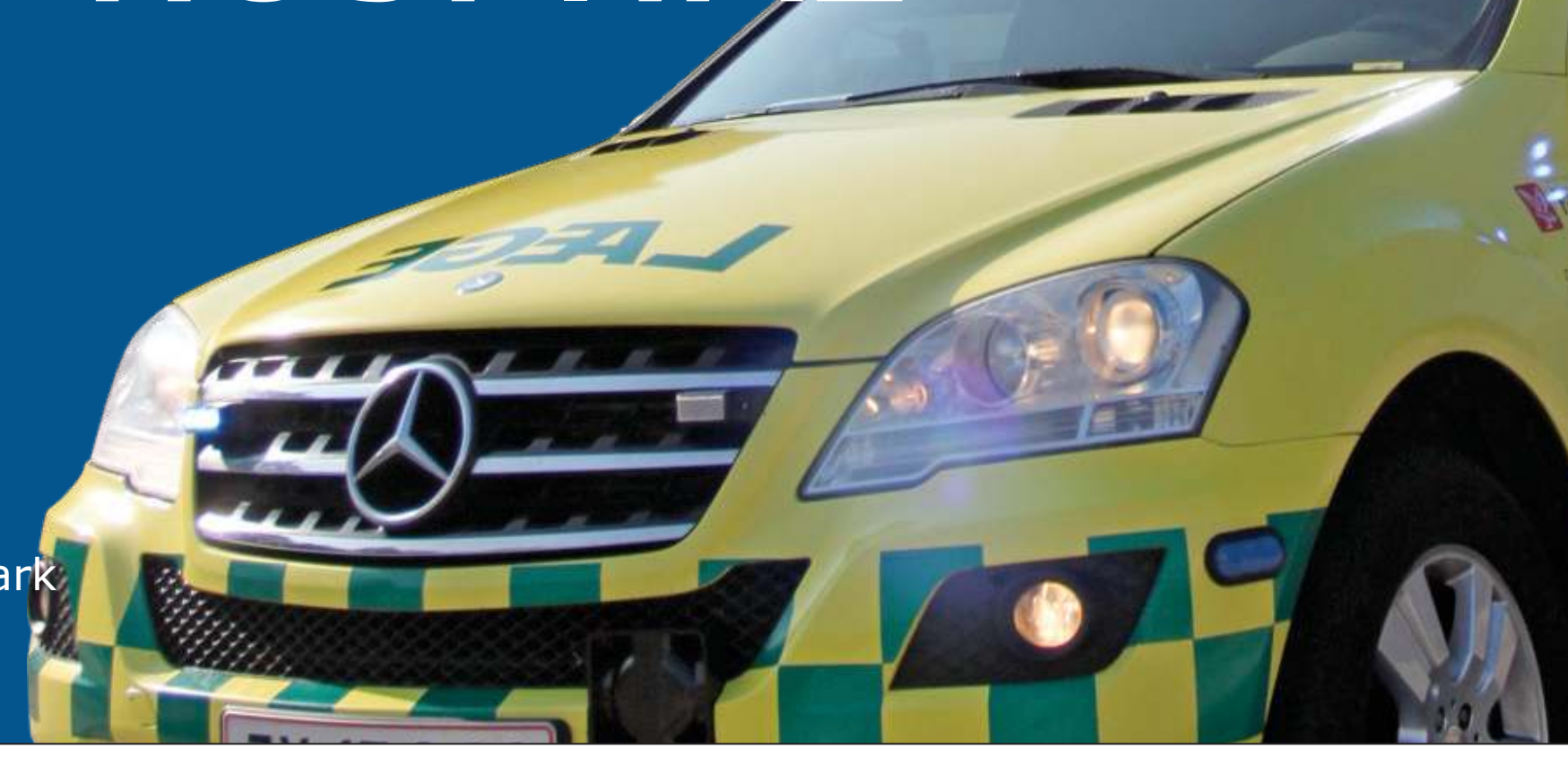

SELF-REPORTED BENEFIT OF ARTERIAL BLOOD GAS ANALYSIS

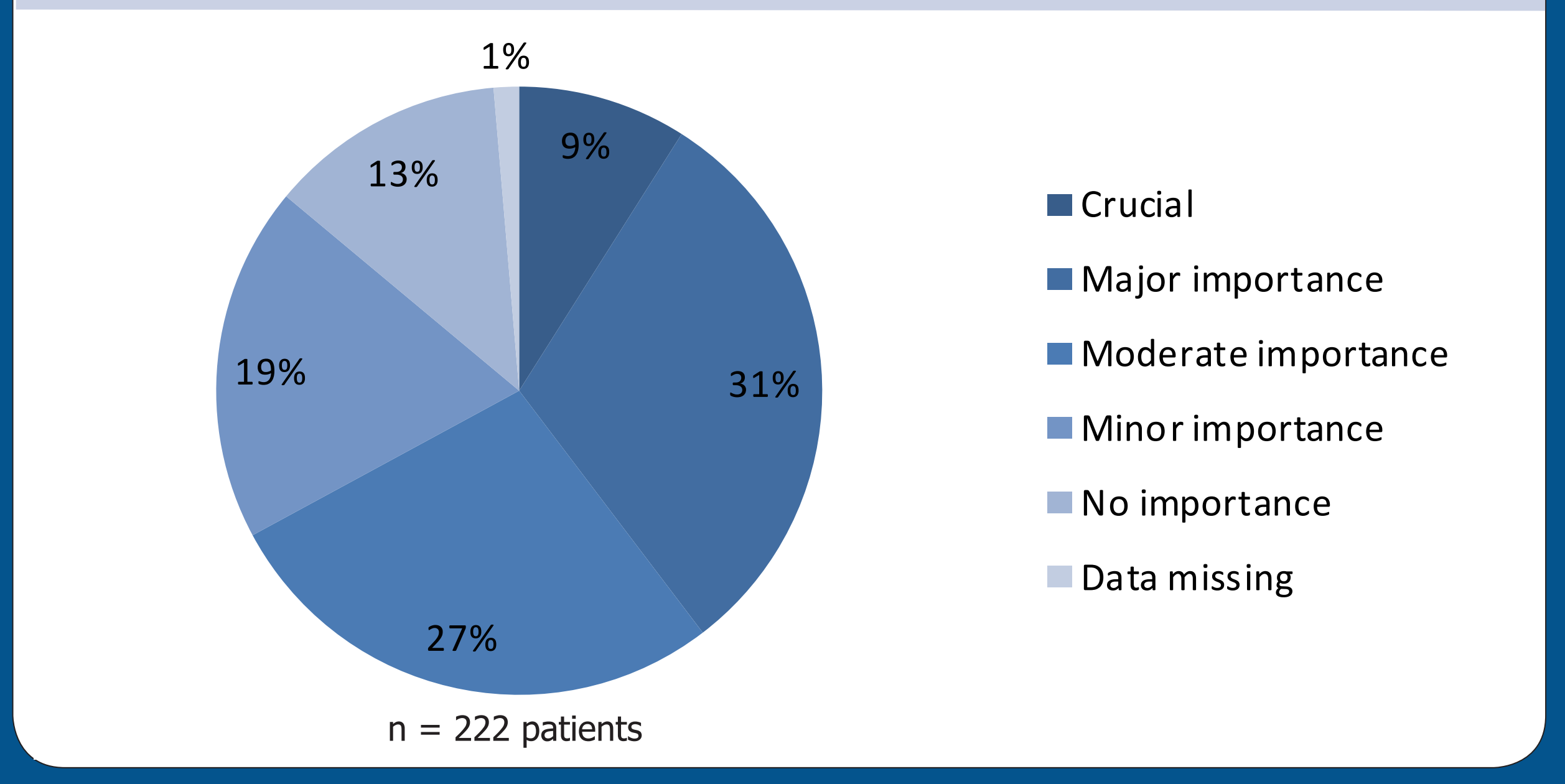

\section{CONCLUSION}

Although pre-hospital ABG did not affect the percentage of observational and symptomatic diagnoses, the EPs reported that pre-hospital ABG improved the precision of pre-hospital diagnosis and quality of treatment in patients with acute critical illness and $\mathrm{GCS}<13$.

\section{CONTACT}

Søren Mikkelsen

soeren.mikkelsen@rsyd.dk

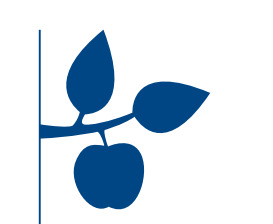

UNIVERSiTY OF SOUTHERN DENMARK
OUH

04

University Hospita 